\title{
Business Intelligence in the Service of Libraries
}

\begin{abstract}
Business intelligence (BI) refers to methodologies, analytical tools, and applications used for data analysis of business information. This article aims to illustrate an application of BI in libraries, as reporting modules in library management systems are usually inadequate for a comprehensive business analysis. The application of BI technology is presented as a case study of libraries using the BISIS library management system in order to overcome shortcomings of an existing reporting module. Both user requirements regarding reporting in BISIS and already existing transactional databases are analysed during the development of a data warehouse model. Based on that analysis, three data warehouse models have been proposed. Also, examples of reports generated by an OLAP tool are given. By building the data warehouse and using OLAP tools, users of BISIS can perform business analysis in a more user-friendly and interactive manner. They are not limited with predefined types of reports. Librarians can easily generate customized reports tailored to the specific needs of the library.
\end{abstract}

\section{INTRODUCTION}

Organizations usually have a vast amount of data which increases on a daily basis. The success of an organization is directly related to its ability to provide relevant information in a timely manner. An organization must be able to transform raw data into valuable information that will enable better decision-making. ${ }^{1}$ For this reason, it is impossible to imagine an organization without an efficient reporting module as a part of its management information system. If we put libraries in a business context, they are very similar to any other organization. The common characteristic of each is that they have high demand for a variety of statistical reports in order to support their business.

A library management system uses a transactional database to store and process relevant data. This database is designed in accordance with the main functionalities of the system. Information used to make strategic decisions is usually obtained from historical and summarized data. However, the database model may have a complex structure and may not be suitable for performing analytical queries that are often very complex and involve aggregations. Execution of those queries may be a time-consuming and resource-intensive process that can decrease performance as well as the availability of the system itself. Also, creating such queries can require advanced IT knowledge. These problems can be overcome by developing business intelligence systems.

Business intelligence (BI) refers to methodologies, analytical tools, and applications used for data analysis of business information. BI gives business managers and analysts the ability to conduct

Danijela Tešendić (tesendic@uns.ac.rs) is Associate Professor, University of Novi Sad. Danijela Boberić Krstićev (dboberic@uns.ac.rs) is Associate Professor, University of Novi Sad. 
appropriate analyses. By analyzing historical and current data, decision-makers get valuable insights that enable them to make better, more-informed decisions. BI systems rely on a data warehouse as an information source. The data warehouse is a repository of data usually structured to be available in a form ready for analytical processing activities. ${ }^{2}$

Business intelligence systems do not exist as ready-made solutions for each organization, but need to be built in accordance with the characteristics of each organization using the appropriate methodology. This article proposes a data warehouse architecture and usage of OLAP tools in order to support BI in libraries. The application of BI technology is illustrated through a case study of libraries using the BISIS library management system. The first step in implementation of BI was the creation of a data warehouse model considering data that exist in BISIS and requirements regarding reporting. After the data warehouse model had been created, data were loaded into the data warehouse using OLAP tools. OLAP tools were also used for visualization of data stored in the data warehouse.

\section{REPORTING IN BISIS}

The BISIS library management system has been in development since 1993 by the University of Novi Sad, Serbia. Currently, the BISIS community comprises over forty medium-sized libraries in Serbia. ${ }^{3}$ The primary modules of the BISIS system include cataloguing, reporting, circulation, OPAC, bibliographic data interchange, and administration. BISIS supports cataloguing according to UNIMARC and MARC 21 formats using an XML editor for bibliographic material processing. ${ }^{4}$ The BISIS search engine is implemented with a Lucene engine. ${ }^{5}$ BISIS supports Z39.50 and SRU protocols for the search and retrieval of bibliographic records. ${ }^{6}$ Those protocols are also used for developing a BISIS service for searching and downloading electronic materials by the audio library system for visually impaired people. ${ }^{7}$ In addition, BISIS allows sharing of bibliographic records with the union catalogue of the University of Novi Sad. ${ }^{8}$ The circulation module features all standard activities for managing users: registration, charging, discharging, searching users and publications, and generating different kinds of reports, as well as user reminders. ${ }^{9}$

The reporting module of BISIS is implemented using the JasperReports tool. ${ }^{10}$ However, this module has some limitations due to the fact that BISIS works only with a transactional database and does not cope well with complex reports. Firstly, in order to generate reports regarding library collections, it is necessary to process all bibliographic records stored in that transactional database. This activity significantly burdens the system and reduces its performance. To avoid this, reports are prepared in advance outside working hours, usually at night. Consequently, those reports include only data collected before report generation. Creating reports in this manner greatly reduces system load and speeds up presentation of the reports because they are already generated. However, some reports, such as those related to the financial aspects of the library (e.g., the number of new members and the balance at the end of the day), need to be created in real time. Due to the execution in real time, those reports are ineffective and affect the performance of the entire system.

The next limitation of this reporting module is that it has a set of predefined reports and the creation of new reports requires additional development. In the current deployment it is not possible to add new reports without engaging software developers. Also, an additional obstacle is the fact that the data for generating reports are obtained from two different data sources (described in more detail in the following sections). For example, the report regarding the number 
of borrowed books by the UDC (Universal Decimal Classification) groups requires data about the UDC groups from XML documents and data about book borrowing from the relational database. Generating this kind of reports cannot be done in a timely and efficient manner.

Taking into account these shortcomings of the reporting module, it can be concluded that the application of business intelligence, primarily data warehouse and OLAP tools, could improve analytical data processing in the libraries using BISIS.

\section{RELATED WORK}

One of the basic components of the business intelligence system is a data warehouse. A data warehouse is a centralized database that stores historical data. Those data are in principle unchangeable and they are obtained by collecting and processing data from various data sources. Data warehouses are used as support for making business decisions. ${ }^{11}$ The data sources for a data warehouse can be diverse and may include transactional databases and different file formats. The process of integrating data from different data sources into a single database is called data warehousing. Data warehousing includes extracting, transforming, and loading (ETL) data into data warehouse. ${ }^{12}$ The goal of data warehousing is to extract useful data for further analysis from the huge amount of data that is potentially available.

There are different approaches to modeling a data warehouse. These approaches can be classified in three different paradigms according to the origin of the information requirements: (1) supplydriven, (2) demand-driven, and (3) hybrids of these. A supply-driven approach is based on data that exist in the transactional database. These data are analyzed to determine which data are the most relevant for making business decisions, or which data should be part of the data warehouse. Alternatively, a demand-driven approach is based on the end-user requirements which means that the data warehouse is modeled in a way that is possible to get answers to the questions asked by the users. The third approach is a hybrid approach and it combines the previous two approaches in the process of data warehouse modelling. The hybrid approach attempts to diminish the shortcomings of the previous two approaches. In the case of a supply-driven approach, the data warehouse will probably not meet the requirements of the end users, while in the demand-driven approach there may be no data to fill the created data warehouse. In an article published in 2009, Romero and Abelló gave an overall view of the research in the field of dimensional modeling of data warehouses. ${ }^{13}$

Various examples of implementation of data-warehouse solutions in libraries can be found in the literature. In 2014, Siguenza-Guzman et al. described the design of a knowledge-based decision support system based on data-warehouse techniques that assists library managers making tactical decisions about the optimal use and leverage of their resources and services. When designing the data warehouse, the authors started from the requirements of the end users (demand-driven approach) and extracted data from heterogeneous sources. ${ }^{14}$ A similar approach has been used by Yang and Shieh, who started from the reports needed by public libraries in Taiwan and through an iterative methodological approach modeled a data warehouse that meets all their reporting requirements. ${ }^{15}$

Unlike the previously described articles where a demand-driven approach was used, we applied a hybrid approach to modeling data warehouse. We analyzed data sources that exist in BISIS 
following a supply-driven approach, but we also analysed user requirements to identify the facts and dimensions for the dimensional data warehouse model.

\section{MODELING THE DATA WAREHOUSE}

In order to implement a data warehouse solution, the first step is to design a data model suitable for analytical data processing. A data warehouse usually stores data in a relational database and organizes them in so called dimensional models. Unlike standard relational database models, those models are denormalized and provide easier data visualization. Data can be presented as a cube with three, four or $n$-dimensions. Analyzing such data is more intuitive and user-friendly.

The dimensional model contains the following concepts: dimensions, facts, and measures. Dimensions represent the parameters for data analysis while facts represent business entities, business transactions, or events that can be used in analyzing business processes. The most commonly used model in dimensional modeling is the star model. After identifying the facts and dimensions, a dimensional model almost always resembles a star, with one central fact and several dimensions that surround it. Dimensions and facts are usually implemented as tables in the relational database. Dimension tables contain primary keys and other attributes. Fact tables contain numerical data as well as dimension tables keys. The measure is a numerical attribute of the fact table and can be obtained by aggregating data by certain dimensions.

There are several approaches to modeling data warehouse and we followed a hybrid approach to design dimensional models presented in this article. This implies that both the existing data sources and the user requirements were considered while designing the final data-warehouse models. That modeling process involved the following activities:

1. analysis of existing data sources in BISIS with identification of possible facts and dimensions,

2. analysis of user requirements regarding reporting,

3. refactoring of the facts and dimensions in accordance with the user requirements, and

4. design of dimensional models.

\section{Analysis of Data Sources in BISIS}

The first step in creating a data warehouse is an analysis of existing data sources. The BISIS system uses two different data sources. Bibliographic records are stored in XML documents, while circulation data, as well as holdings data regarding the items that are circulated, are stored in a relational database.

In 2009, Tešendić et al. described the BISIS circulation database model. ${ }^{16}$ That model describes data about individual and corporate library members. Data about members includes information about personal data, membership fees, as well as information about a member's borrowed and returned items.

Bibliographic data in BISIS are presented in UNIMARC format. Dimić and Surla in 2009 described the model for bibliographic records used in BISIS. ${ }^{17} \mathrm{~A}$ bibliographic record is modeled as a list of fields and subfields. A field contains a name, values of the indicators and a list of subfields. A subfield contains a name and a value of that subfield. The data described by that model are stored in XML documents because the bibliographic record structure is not suitable for relational modeling. That structure is more in line with the document-oriented data storage approach. 


\section{Analysis of User Requirements}

One of the essential functionalities of information systems, including library management systems, is to provide various statistical reports that should help the management of the library to make better business decisions. User requirements related to analytical processing in BISIS can be grouped into several categories.

The first category consists of requirements regarding reports on the library collections. Examples of reports from this category are:

- number of publications per language for a certain period of time;

- number of publications by departments;

- number of new publications for a certain period of time; and

- number of publications by UDC groups.

The second category consists of requirements related to the circulation of library resources. Examples of such reports are:

- number of borrowed items by member category;

- number of borrowed items by language of publication;

- number of borrowed items by departments;

- the most popular books; and

- the most avid readers for a certain period.

The third category consists of requirements related to the reports on financial elements of the library's business. Some of the reports are:

- number of new members on a daily basis with a financial balance;

- number of members by membership category and gender; and

- number of members per departments.

Analyzing user requirements, it was perceived that a new data warehouse have to be created using data from both data sources. This means that appropriate transformations of data from the relational database as well as from the bibliographic records documents need to be performed.

\section{DATA WAREHOUSE MODELS}

Taking into account the reporting requirements as well as the data that exist in BISIS, appropriate dimensional models are designed. The proposed dimensional models were designed to meet all the needs for analytical processing, as well as to enable flexibility of the reporting process in BISIS. For each of the observed groups of reports, a dimensional model was created as described below.

\section{Model Describing Library Collection Data}

A dimensional model of the BISIS data warehouse used for analytical processing of the library collection data is shown in figure 1.

The data from this model are used to generate reports on the library collection. Examples of such reports are accessions register, number of items by UDC group, number of items by departments, etc. In generating all these reports, an acquisition number of an item has the main role and all reports are created either by counting the acquisition numbers or by displaying the acquisition 
numbers along with other data related to that item. Therefore, the acquisition number represents the measure in this dimensional model. The central table in the model is the Item table and it presents a fact table. This table contains the acquisition number and foreign keys from dimension tables.

All other tables in the model are dimension tables. The Publication table represents a dimension table containing bibliographic data from bibliographic records. Only data that are needed for reports are extracted from bibliographic records and stored in this table. Those data refer to the name of the author, the title of the publication, the publication's ISBN and UDC number, the number of pages, keywords, and an identification number for the bibliographic record in the transactional database. The Acquisition table represents a dimension that describes the publication's acquisition data such as a retail price, the name of the supplier, and the invoice number. The Location table describes departments within the library where an item is stored. The Status, Publisher, Language, and UDC_group tables relate to information about the status of an item, publisher, language of the publication, and UDC group to which an item belongs. The Date and Year tables represent the time dimensions. Data in the Date table are extracted from the date of an item acquisition and data in the Year table are extracted from the publishing year.

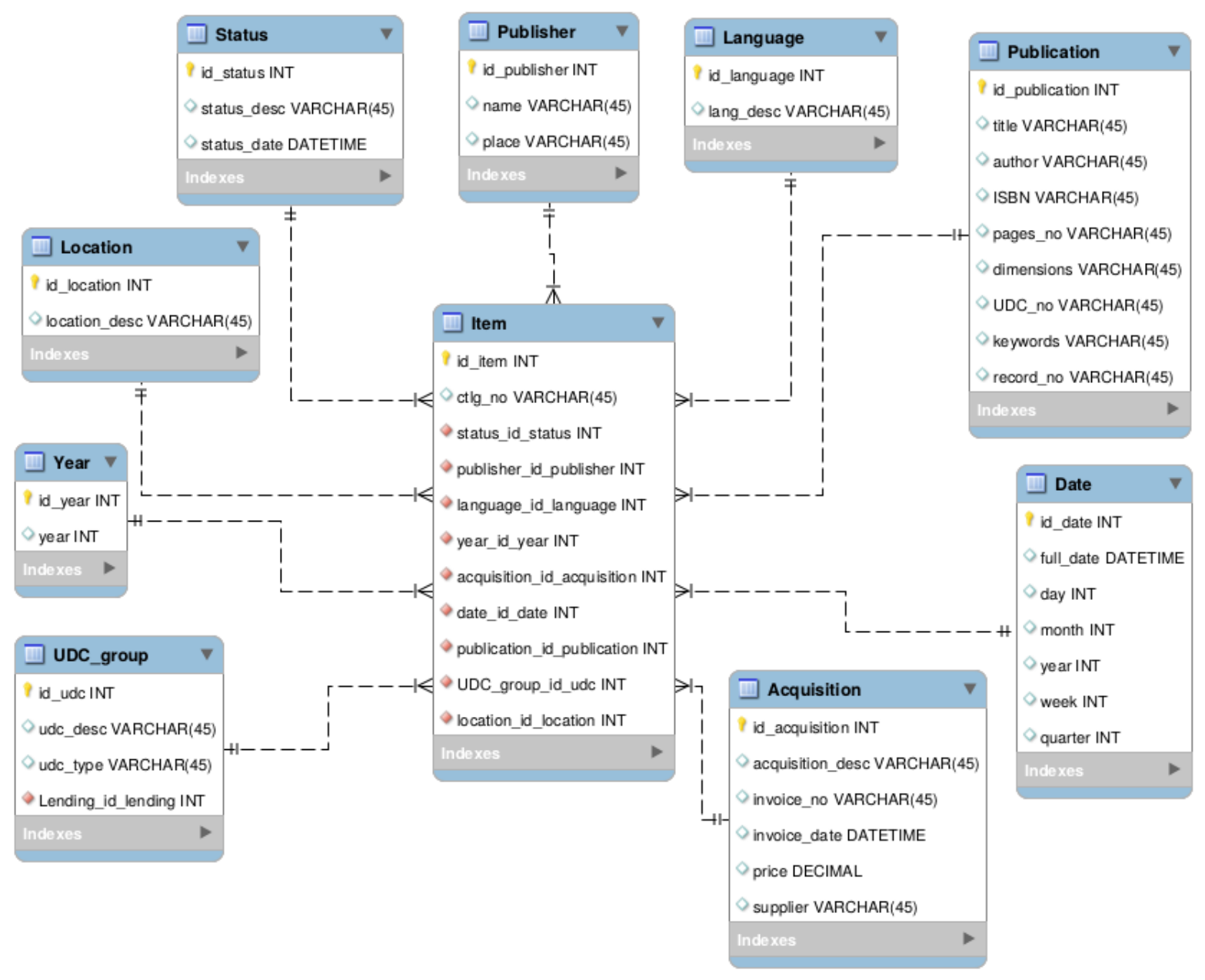

Figure 1. Dimensional model describing library collection data. 


\section{Model Describing Library Circulation Data}

A dimensional model of the BISIS data warehouse used for the analytical processing of library circulation data is shown in figure 2 .

Data from this model are used for generating statistical reports regarding usage of library resources. Examples of such reports are the number of borrowed publications according to different criteria (such as user categories, language of publication, departmental affiliation of the user who borrowed the publication, etc.). These data can answer questions about the most popular books or the readers with the highest number of borrowed books. Similar to the previous reporting group, the acquisition number of the item which was borrowed has the main role in generating those reports. All reports from this group are created by counting acquisition numbers of borrowed items and displaying data related to those checkouts. Therefore, in this dimensional model, the acquisition number is a measure. The central table in the model is the Lending table and is presented as a fact table. This table contains the acquisition number of the borrowed item and foreign keys from the dimension tables.

All other tables in the model are dimension tables. The Publication, Publisher, Year, Acquisition, UCD_group, Status, and Language tables contain data from bibliographic records and the content of these tables have been already explained. The Member, MembershipType, Category, Education, and Gender tables represent the dimension tables containing information about library users. These data are only a subset of circulation data from transactional database. The Location table describes departments within the library where items are borrowed. The Date table represents the time dimension. The data in the Date table are derived from the date of borrowing and the date of discharge of an item. 


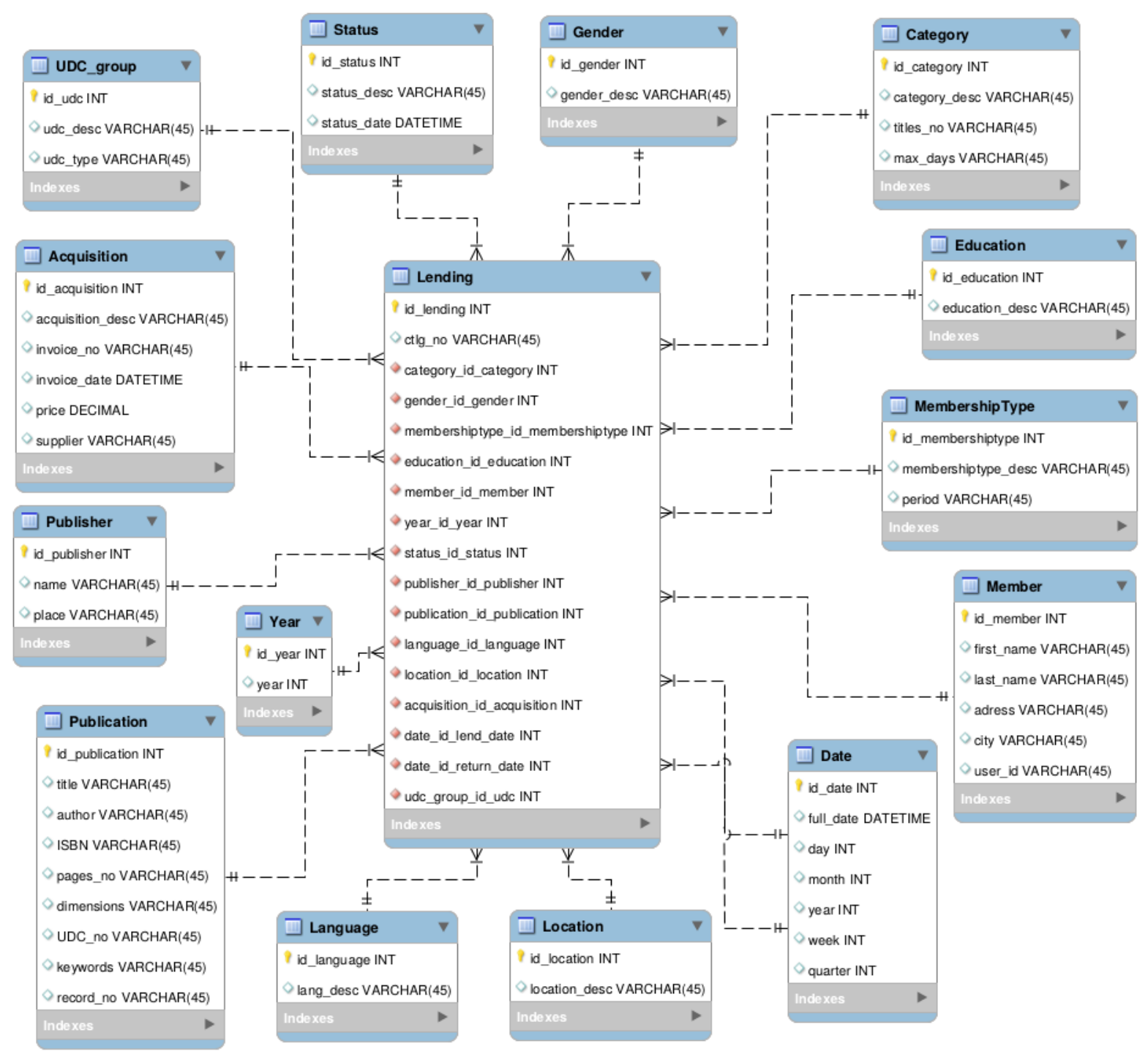

Figure 2. Dimensional model describing library circulation data.

\section{Model Describing Members' Data}

A dimensional model of the BISIS data warehouse used for the analytical processing of members' data is shown in figure 3.

Data from this model are used for generating statistical reports on library members, as well as for generating financial reports based on membership fees. Examples of such reports are the number of members according to different criteria (such as department of registration, member category, type of membership, gender, or education level). Also, this report group contains reports that include a financial balance (for example, a list of members with membership fees in a certain time period). The membership fee has the main role in generating these reports. All reports from this group are generated by counting or displaying members who have paid a membership fee or summarizing membership fees. Therefore, in this dimensional model, membership fee is a measure. The main table in the model is the Membership table and it presents a fact table. It contains the membership fee, which is the measure, and foreign keys from the dimension tables. 
All other tables in the model are dimension tables. Tables Member, MembershipType, Category, Education and Gender represents the dimension tables that contain information about library members and the content of these tables was previously described. The table Location describes departments within the library where user registration is performed. The table Date represents the time dimension. Data in the table Date are based on the registration date and the date of the membership expiration.

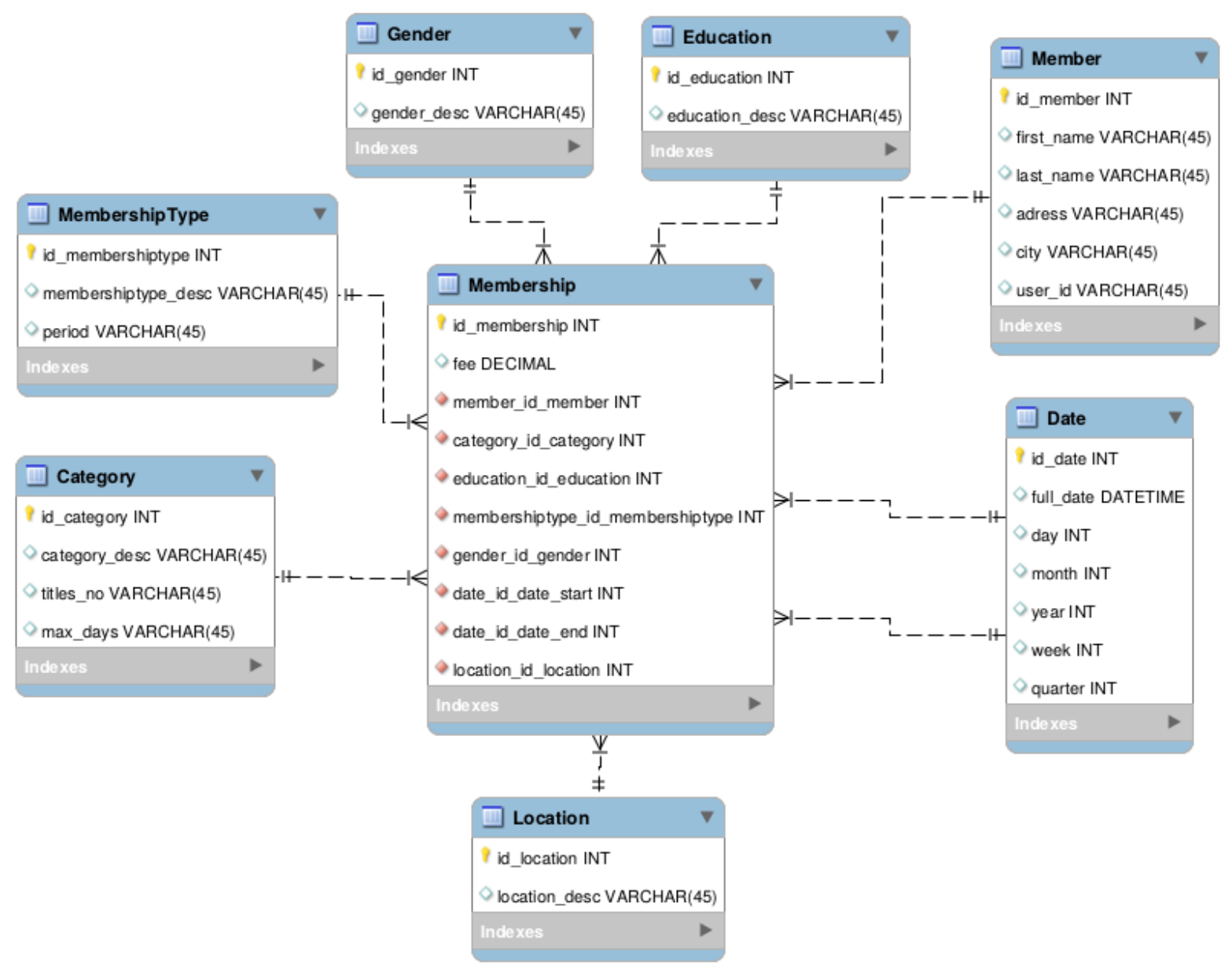

Figure 3. Dimensional model describing library members.

\section{TRUE VALUE OF A DATA WAREHOUSE}

In the previous sections, we presented models of data warehouse, but those models are unusable if they are not implemented and populated with data needed for business analysis. Extracting, transforming, and loading (ETL) processes are responsible for reshaping the relevant data from the source systems into useful data to be stored in the data warehouse. ETL processes load data into a data warehouse, but that data warehouse is still only storage for those data. A real-time and interactive visualisation of those data will show the true benefits of data warehouse implementation in various organisations including libraries.

To load as well as to analyze and visualize large volumes of data in data warehouses, various OnLine Analytical Processing (OLAP) tools can be used. ${ }^{18}$ The usage of OLAP tools does not 
require a lot of programming knowledge in comparison to tools used for querying transactional databases. The interface of OLAP tools should provide a user with a comfortable working environment to perform analytical operations and to visualize query results without knowing programming techniques or structure of transactional database.

There are various OLAP tools available on the market. ${ }^{19}$ When choosing an OLAP tool to be used in an organization, there are several important criteria to consider: the duration of query execution, user-oriented interface, the possibility of interactive reports, price of tool, automation of the ETL process, etc. ${ }^{20}$ Pentaho BI system is one of the open-source OLAP tools which satisfies most of those criteria. Among various features, Pentaho supports creation of ETL processes, data analysis, and reporting. ${ }^{21}$ Implementation of ETL processes can be a challenging task primarily because of the nature of the source systems. We used Pentaho tool to transform data from BISIS to the data warehouse, as well as to visualize data and generate statistical reports.

\section{ETL Processes Modeling}

After creating a data-warehouse model, it is necessary to load data into the data warehouse. The first step in that process is to extract data from the data sources. Those data may not be in accordance with the newly created data-warehouse model and appropriate transformations of data may be needed before loading.

Regarding the structure of the data sources, transformations can be implemented from scratch, or by using dedicated OLAP tools. Both techniques are used in the development of our data warehouse. Transformations that required data from bibliographic records were implemented from scratch because of complex data structure, while transformations that processed data from relational database are implemented using Pentaho Data Integration (PDI) tool. PDI is a graphical tool that enables designing and testing ETL processes without writing programming code. Figures 4 and 5 show an example of transformations created and executed by that tool. Those transformations have been applied to load members' data from BISIS relational database into the data warehouse.

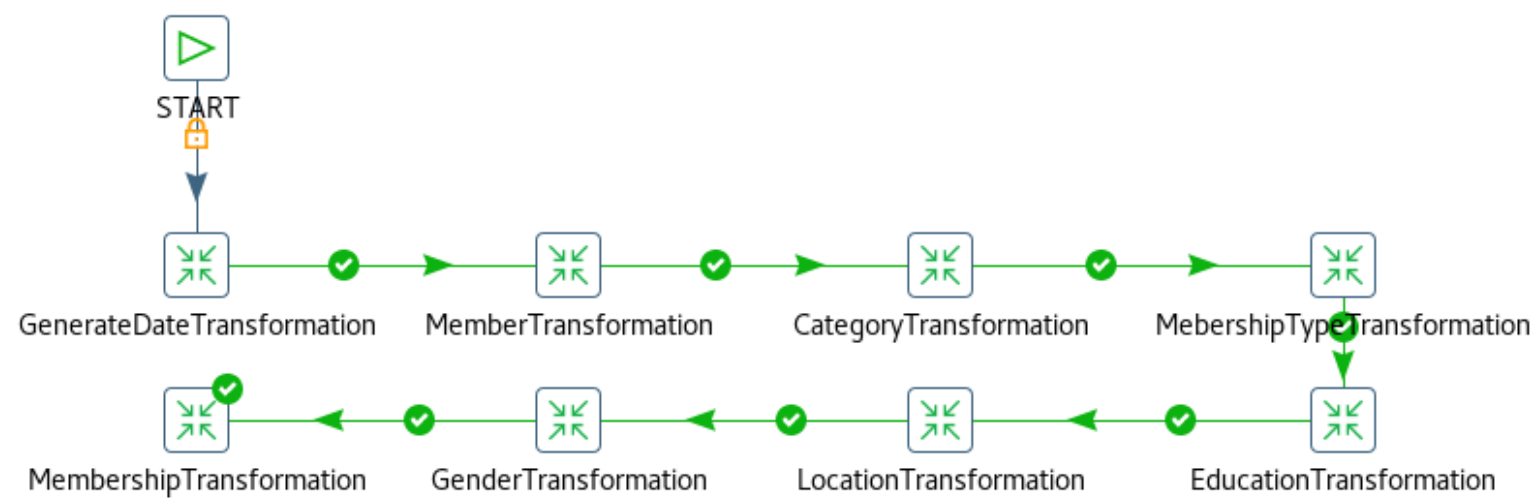

Figure 4. Transformations for loading members data. 


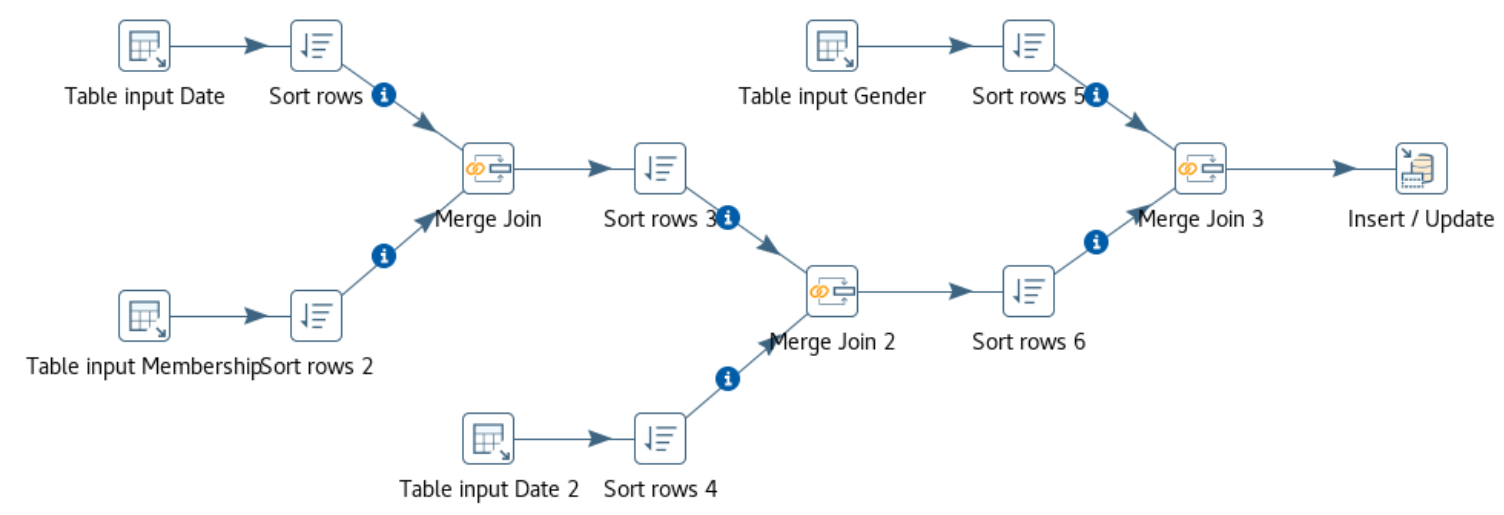

Figure 5. The MembershipTransformation process.

An issue that may arise after an initial loading of a data warehouse relates to updating the data warehouse. In order to achieve a better performance of transactional databases, updates of the data warehouse should not be performed in real time. In the case of library management systems, those updates can be performed outside of working hours so data in the data warehouse will be up to date on a daily basis. An update algorithm can be defined as an ETL process using OLAP tools or it can be implemented from scratch.

\section{Data Visualization}

The basic task of OLAP tools is to enable visualization of data stored in a data warehouse. The OLAP tools use multidimensional data representation, known as a cube, which allows a user to analyze data from different perspectives. OLAP cubes are built on dimensional models of a data warehouse and consist of dimensions and measures. Dimensions form the cube structure and each cell of the cube holds a measure. Measures are derived from the records in the fact table and dimensions are derived from the dimension tables. OLAP tools allow a user to select a part of the OLAP cube by setting an appropriate query and that part can be further analyzed by different dimensions. This process is performed by applying common operations on the cube which include slice and dice, drill down, roll up, and pivot. ${ }^{22}$ Data that are results of operations on the cube can be visualized in the form of tables, charts, graphs, maps, etc.

The main advantage of OLAP tools reflects is that end users can do their own analyses and reporting very efficiently. Users can extract and view data from different points of view on demand. OLAP tools are valuable because they provide an easy way to analyze data using various graphical wizards. By analyzing data interactively, users are provided with feedback which can define the direction of further analysis.

In order to visualize data from our data warehouse, we used the Pentaho OLAP tool. We used it to create predefined reports identified during the analysis of user requirements as well as some interactive reports using operations on the OLAP cube. Examples of generated reports are presented below in order to illustrate some features of the Pentaho OLAP tool.

An example of a report shown in figure 6 was obtained with a dice operation on the cube. The dice operation selects two or more dimensions from a given cube and provides a new sub-cube. In this particular example, we selected three dimensions: gender, member category, and registration date. 


\section{File View Tools Help \\ Opened $\checkmark$ ए}

numberByCategoryAndGender

\section{Number of members grouped by category and gender}

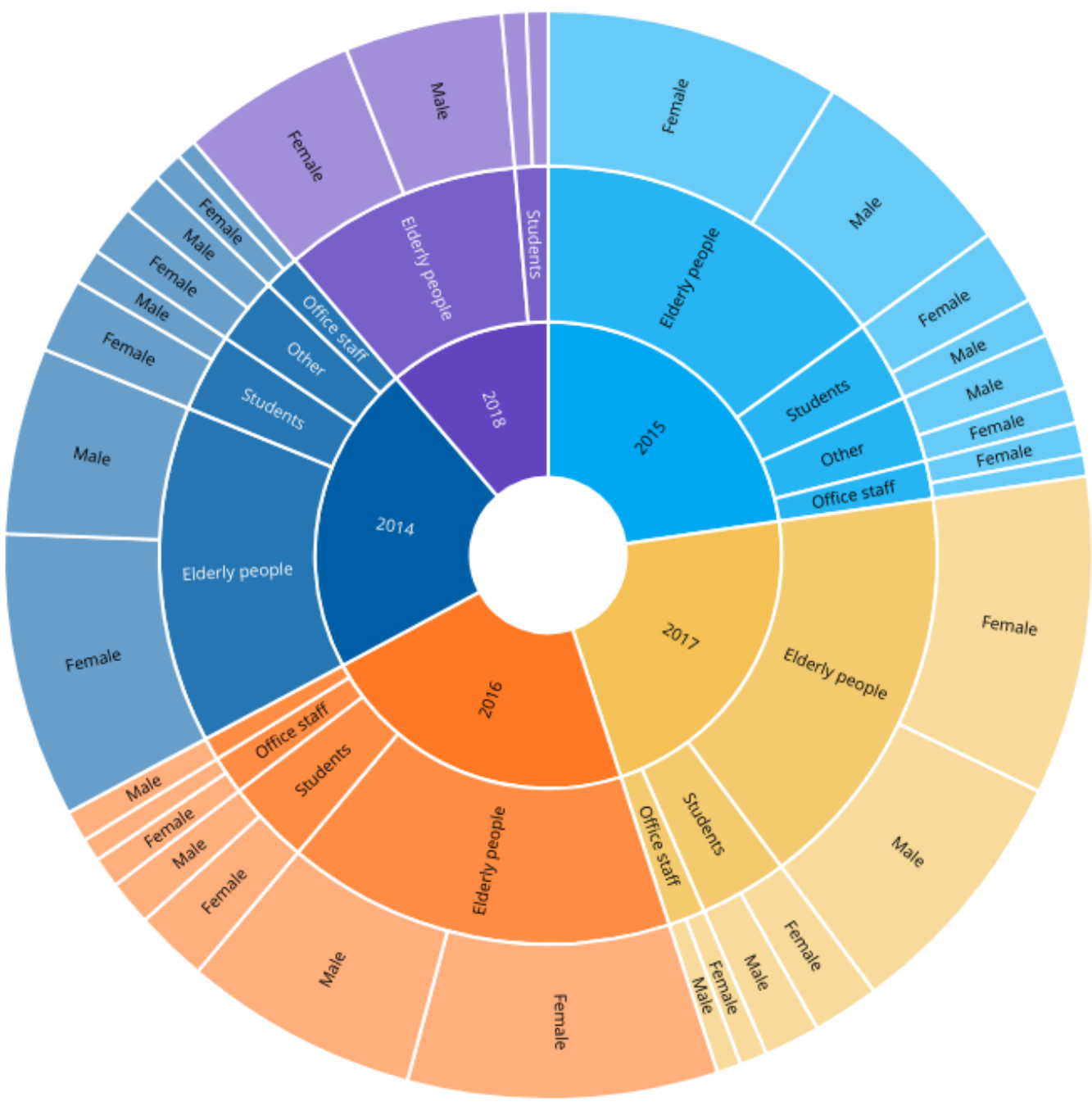

Figure 6. Example of dice operation performed on the OLAP cube. 


\section{File View Tools Help}

\section{Opened $\sim$ \\ 田 \\ B BO}

Editing:bisis_cde $\times$ publication_by_year.xjpivot

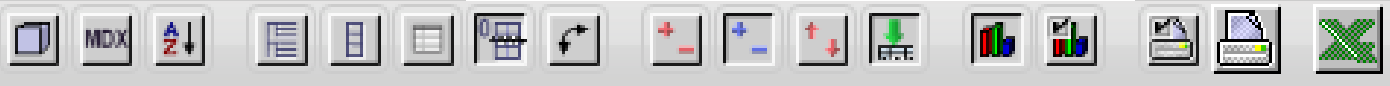

\begin{tabular}{|c|c|c|c|c|c|c|c|c|}
\hline \multirow[b]{2}{*}{ Measures } & \multicolumn{8}{|l|}{ Date } \\
\hline & ${ }^{\ddagger} 2010$ & ${ }^{\ddagger} 2012$ & Ð 2013 & 2014 & ${ }^{\ddagger} 1$ & $\boxplus 2$ & $\$ 3$ & $₫ 4$ \\
\hline Item & $\cdot 5.392$ & $\cdot 8.178$ & $\cdot 5.313$ & $\cdot 4,387$ & .566 & .865 & $\cdot 1.110$ & $\bullet 1,846$ \\
\hline
\end{tabular}

Slicer:

\begin{tabular}{|c|c|c|c|c|c|c|c|}
\hline \multicolumn{7}{|c|}{ E Drill Through Table for id_item } & \multirow[t]{2}{*}{$\otimes$} \\
\hline - year & - quarter & - month & \multicolumn{2}{|c|}{ - author } & \multicolumn{2}{|c|}{ - title } & \\
\hline 2014 & 3 & 7 & \multicolumn{2}{|c|}{ Голдинг, Вилијам } & \multicolumn{3}{|l|}{ Naslednici } \\
\hline 2014 & 3 & 7 & \multicolumn{2}{|c|}{ Грифин, Николас } & \multicolumn{3}{|c|}{ Kuća videla i senke } \\
\hline 2014 & 3 & 7 & \multicolumn{2}{|c|}{ Гујон, Арно } & \multicolumn{3}{|c|}{ Svi moji putevi vode ka Srbiji } \\
\hline 2014 & 3 & 7 & \multicolumn{2}{|c|}{ Дајер, Вејн В. } & \multicolumn{3}{|c|}{ Do uspeha - bez izgovora! } \\
\hline 2014 & 3 & 7 & \multicolumn{2}{|c|}{ Дајер, Вејн В. } & \multicolumn{3}{|c|}{ Do uspeha - bez izgovora! } \\
\hline 월 $\mathrm{F}$ & Page $10 / 22$ & 2 느릴 & oto Page & 10 & I] Rows/page & 5 & (] \\
\hline
\end{tabular}

Number of publications per year

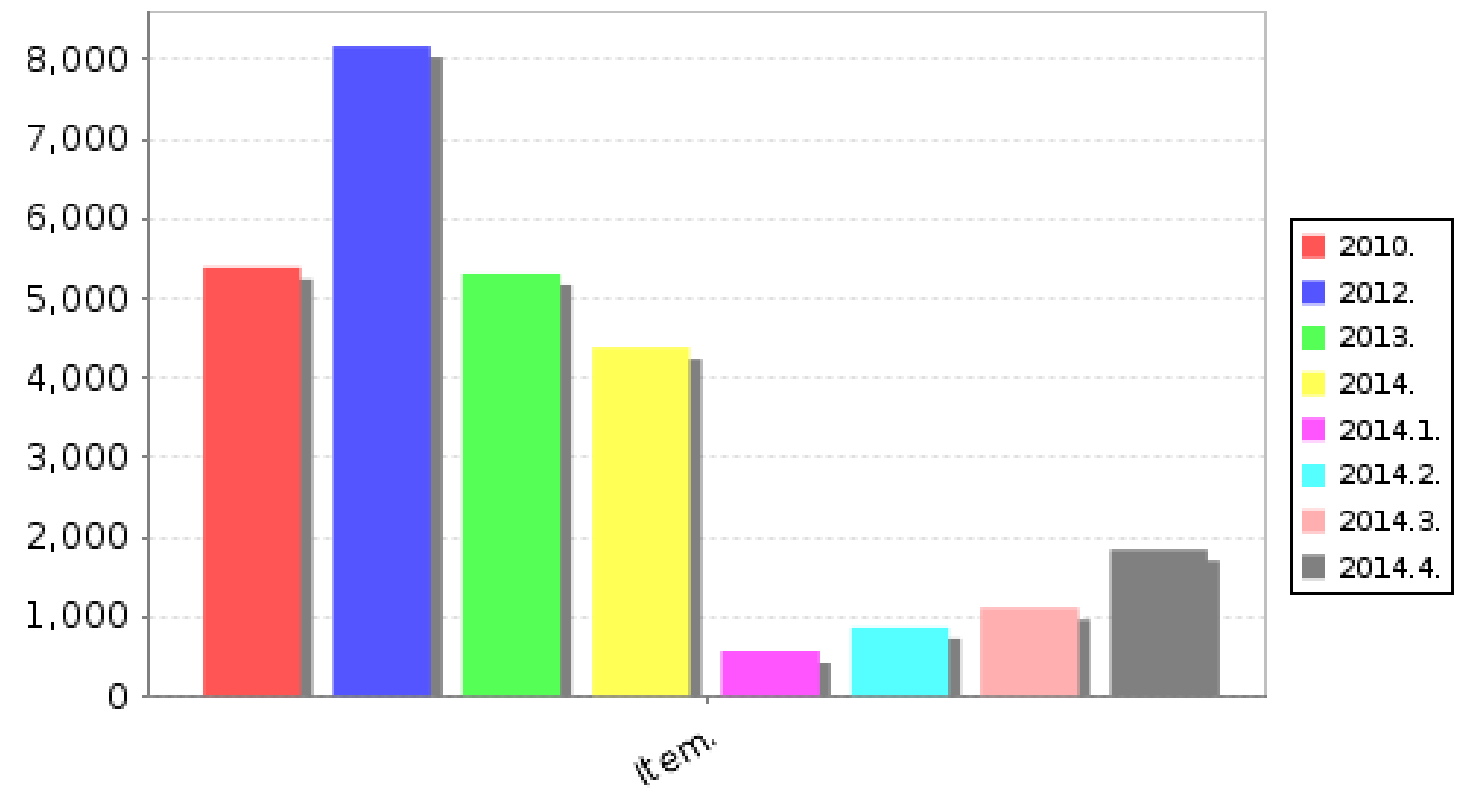

Figure 7. Example of roll-up and drill-down operations performed on the OLAP cube. 
Additionally, we analyzed only those data from 2014 to 2018 . The result of this operation is presented in the form of nested pie charts. However, other forms of visualisation can be applied on the same data set very easily.

In figure 7, a more complex report is presented. That report is obtained by performing combination of roll-up and drill-down operations. The roll-up operation performs aggregation on a cube reducing the dimensions. In our example, we aggregated the number of newly acquired publications for certain years ignoring all other dimension except the date dimension. A user can select a particular year, quarter, and month and analyze details of purchased publications in that period, such as title and author of the publication. This is an example of using drill-down operation on the cube. The result of that operation is presented as a table, as shown in figure 7. This report is interactive, because user can investigate data in more detail by performing other operations on the cube that are placed on the toolbar of the report.

\section{CONCLUSION}

This article aims to illustrate an application of business intelligence in libraries, as reporting modules in library management systems are usually inadequate for a comprehensive business analysis. Development of a data warehouse, which is the base of any business intelligence system, as well as usage of OLAP tools are presented. Both user requirements regarding reporting in BISIS and already-existing transactional databases are analyzed during the development of a datawarehouse model. Based on that analysis, three data-warehouse models have been proposed. Also, examples of reports generated by an OLAP tool are given.

By building the data warehouse and using OLAP tools, users of BISIS can perform business analysis in a more user-friendly manner than with other processes. Users are not limited to predefined types of reports. Librarians can easily generate customized reports tailored to the specific needs of the library. In this way, librarians work in a more comfortable environments, performing analytical operations interactively and visualizing query results without additional programming knowledge. The article presents the usage of Pentaho OLAP tool, but the proposed data-warehouse model is independent of OLAP tools selection and any other tool can be integrated with the proposed data warehouse.

\section{REFERENCES}

${ }^{1}$ Ralph Stair and George Reynolds, Fundamentals of Information Systems (Cengage Learning, 2017).

${ }^{2}$ Ramesh Sharda, Dursun Delen, and Efraim Turban, Business Intelligence, Analytics, and Data Science: A Managerial Perspective (Pearson, 2016).

3 “BISIS," library management system BISIS, accessed July 8, 2019, http://www.bisis.rs/korisnici/.

4 Bojana Dimić and Dušan Surla, "XML Editor for UNIMARC and MARC 21 Cataloguing," The Electronic Library 27, no. 3 (2009): 509-28, https://doi.org/10.1108/02640470910966934; Bojana Dimić Surla, "Eclipse Editor for MARC Records," Information Technology and Libraries 31, no. 3 (2012): 65-75, https://doi.org/10.6017/ital.v31i3.2384; Bojana Dimić Surla, "Developing an Eclipse Editor for MARC Records using Xtext," Software: Practice and Experience 43, no. 11 (2013): 1377-92, https://doi.org/10.1002/spe.2140. 
${ }^{5}$ Branko Milosavljević, Danijela Boberić, and Dušan Surla, "Retrieval of Bibliographic Records using Apache Lucene,” The Electronic Library 28, no. 4 (2010): 525-39, https://doi.org/10.1108/02640471011065355.

${ }^{6}$ Danijela Boberić and Dušan Surla,"XML Editor for Search and Retrieval of Bibliographic Records in the Z39. 50 Standard," The Electronic Library 27, no. 3 (2009): 474-95; Danijela Boberić Krstićev, "Information Retrieval using a Middleware Approach," Information Technology and Libraries 32, no. 1 (2013): 54-69, https://doi.org/10.6017/ital.v32i1.1941; Miroslav Zarić, Danijela Boberić Krstićev, and Dušan Surla, "Multitarget/Multiprotocol Client Application for Search and Retrieval of Bibliographic Records," The Electronic Library 30, no. 3 (2012): 351-66, https://doi.org/10.1108/02640471211241636.

${ }^{7}$ Danijela Tesendic and Danijela Boberic Krsticev, "Web Service for Connecting Visually Impaired People with Libraries," Aslib Journal of Information Management 67, no. 2 (2015): 230-43, https://doi.org/10.1108/AJIM-11-2014-0149.

${ }^{8}$ Danijela Boberić-Krstićev and Danijela Tešendić," Mixed Approach in Creating a University Union Catalogue," The Electronic Library 33, no. 6 (2015): 970-89, https://doi.org/10.1108/EL-022014-0026.

${ }^{9}$ Danijela Tešendić, Branko Milosavljević, and Dušan Surla, “A Library Circulation System for City and Special Libraries," The Electronic Library 27, no. 1 (2009): 162-86, https://doi.org/10.1108/02640470910934669; Branko Milosavljević and Danijela Tešendić, "Software Architecture of Distributed Client/Server Library Circulation System," The Electronic Library 28, no. 2 (2010): 286-99, https://doi.org/10.1108/02640471011033648; Danijela Tešendić, "Data Model for Consortial Circulation in Libraries," in Proceedings of the Fifth Balkan Conference in Informatics, Novi Sad, Serbia, September, 16-20, 2012.

${ }^{10}$ Danijela Boberic and Branko Milosavljevic, "Generating library material reports in software system BISIS," in Proceedings of the 4th International Conference on Engineering Technologies ICET, 2009: 133-37.

${ }^{11}$ William H. Inmon, Building the Data Warehouse (Indianapolis: John Wiley \& Sons, 2005); Ralph Kimball, The Data Warehouse Toolkit: Practical Techniques for Building Dimensional Data Warehouses (NY: John Willey \& Sons, 1996), 248, no. 4.

${ }^{12}$ Ralph Kimball and Joe Caserta, The Data Warehouse ETL Toolkit: Practical Techniques for Extracting, Cleaning, Conforming, and Delivering Data (Indianapolis: John Wiley\& Sons, 2004), 528.

${ }^{13}$ Oscar Romero and Alberto Abelló, "A Survey of Multidimensional Modeling Methodologies," International Journal of Data Warehousing and Mining (IJDWM) 5, no. 2 (2009): 1-23.

${ }^{14}$ Lorena Siguenza Guzman, Victor Saquicela, and Dirk Cattrysse, “Design of an Integrated Decision Support System for Library Holistic Evaluation," in Proceedings of IATUL Conferences (2014):112. 
${ }^{15}$ Yi-Ting Yang and Jiann-Cherng Shieh, "Data Warehouse Applications in Libraries-The Development of Library Management Reports," in Advanced Applied Informatics (IIAI-AAI), 2016 5th IIAI International Congress on Advanced Applied Informatics, 88-91. IEEE, 2016, https://doi.org/10.1109/IIAI-AAI.2016.129.

16 Tešendić, Milosavljević, and Surla, “A Library Circulation System,"162-86.

${ }^{17}$ Dimić and Surla, "XML Editor for UNIMARC," 509-28.

${ }^{18}$ Paulraj Ponniah, Data Warehousing Fundamentals for IT Professionals (Hoboken, NJ: John Wiley \& Sons, 2011).

19 “Top 10 Best Analytical Processing (OLAP) Tools," Software Testing Help, https://www.softwaretestinghelp.com/best-olap-tools/.

${ }^{20}$ Rick Sherman, "How to Evaluate and Select the Right BI Tools," https://searchbusinessanalytics.techtarget.com/buyersguide/A-buyers-guide-to-choosingthe-right-BI-analytics-tool.

${ }^{21}$ Doug Moran, "Pentaho Community Wiki," https://wiki.pentaho.com/.

22 Ponniah, "Data Warehousing," 382-93. 